\title{
Happiness and Identities*
}

\author{
Jan E. Stets and Ryan Trettevik \\ University of California, Riverside
}

Word Count: 10,303

Number of Tables: 4

Number of Figures: 1

* Presented at the 2015 International Society for Research on Emotions, Geneva, Switzerland. This research was supported by a National Science Foundation Grant (SES0617022) to the first author. We would like to thank members of the Social Psychology Seminar at the University of California, Riverside for comments on an earlier draft. Address all correspondence to Jan E. Stets, Department of Sociology, University of California, Riverside, CA 92521-0419, jan.stets@ucr.edu 


\begin{abstract}
Previous sociological research has focused on macro forces that are associated with overall happiness with one's life, but it has neglected an analysis of happiness in immediate situations and the micro forces that may shape it. In this study, we examine social structural (gender and race) as well as individual factors (identity and identity verification) that may influence happiness in situations that are morally challenging. Data are examined from an experiment in which satisfying self-interests (doing well on a task to increase the chances of earning money in a lottery) may involve cheating to get ahead. The results reveal that while the distal, structural factors influence happiness for those who do not cheat, proximal, identity factors influence happiness for those who cheat. We discuss how both macro and micro forces may shape happiness in situations.
\end{abstract}




\section{Happiness and Identities}

Happiness has drawn the attention of psychologists far more than sociologists. Part of this may be because psychologists have been influenced by the positive psychology movement that has become increasingly popular over the past 15 years (Power 2015). This movement has encouraged an analysis of human's strengths and virtues rather than human weaknesses and vices. Research on happiness reveals that it is associated with many desirable attributes such as positive self-views, sociability, prosocial behavior, and creativity, as well as successes across major life domains such as work, love, and health (Lyubomirsky, King, and Diener 2005). Happiness is not simply a consequence of these desirable traits and accomplishments, it may also be their cause.

Researchers in sociology have a tendency to focus on social problems or negative states such as poverty or inequality rather than positive states such as generosity or happiness. In studying people's overall happiness, sociologists have examined social structure arrangements and social processes that allocate more resources to some people over others, thus leading to greater happiness among the resource-rich (George 2010). Social factors that have been examined and that are often positively associated with happiness include people's higher position in the stratification system along such dimensions as race/ethnicity, education, income, and marital status (Schnittker 2008a; Yang 2008); their social integration into society such as attending religious services (Yang 2008) or volunteering (Borgonovi 2008); and the social support they receive in social relationships such as friendships and marriage (Schnittker 2008a; Yang 2008).

Psychologists have argued that broad social factors do not account for a significant amount of the variance in happiness (Diener, Suh, Lucas, and Smith 1999), arguing that they explain only about $15 \%$ of the variation in happiness. This may be because people rapidly adapt to their new 
circumstances, and happiness deriving from positive events may be short-lived (Brickman, Coates, and Janoff-Bulman 1978). However, even adaptation theory does not always predict happiness levels. For example, there are individual differences in the rate and extent of adaptation for the same event (Diener, Lucas, and Scollon 2006). Not surprisingly, psychologists maintain that individual factors are stronger correlates of happiness than social factors. They turn to genetic evidence that reveals that one's level of happiness is moderately heritable or relatively fixed, explaining $50 \%$ of the variance in happiness levels (Lykken and Tellegen 1996). ${ }^{1}$ Aside from genetics, they also find that happiness is negatively associated with personality traits such as neuroticism, and positively associated with cognitive factors such as optimism and efficacy, and motivational factors such as the pursuit of goals that are intrinsic in content and consistent with one's values (Diener, Suh, Lucas, and Smith 1999; Lyubomirsky, Sheldon, and Schkade 2005). Taken together, these individual factors claim almost another $40 \%$ of the variance in happiness.

If psychologists have found that individual factors importantly influence happiness, sociologists may need to give more attention to individual processes. One way to do this is through the social comparison process, an activity individuals participate in every day. Essentially, happiness is an outcome of ranking one's current state in relative or comparative terms to an earlier state, to one's current goals, or to some reference group (Diener, Suh, Lucas, and Smith 1999; George 2010; Lyubomirsky 2001). Comparisons can be "upward" in which an association is made with an earlier, more positive condition, a higher goal state, or a reference group that exceeds one's current accomplishments, all of which reduce happiness. Alternatively,

\footnotetext{
${ }^{1}$ Sociologists who study the role of genetics in happiness show that genes matter for some successes related to happiness such as spousal support, but they matter less for other successes such as support from friends (Schnittker 2008b).
} 
comparisons can be "downward" to a poorer earlier condition, lower goal state, or reference group whose successes fall below one's own, and these comparisons can increase happiness.

Social comparison theory has been somewhat popular in trying to understand individual variability in happiness in psychology (Diener, Suh, Lucas, and Smith 1999; George 2010; Lyubomirsky 2001), ${ }^{2}$ but how social comparisons relate to particular kinds of happiness is not always straightforward. ${ }^{3}$ If happiness is the evaluation that the overall quality of one's life is favorable (commonly labeled "subjective well-being") (Diener, Suh, Lucas, and Smith 1999; George 2010; Yang 2008), it has been argued that social comparisons may be less relevant in explaining overall happiness and may be more relevant in understanding happiness in an immediate situation (Veenhoven 1991).

In the current research, we use the lens of social comparison to study micro forces or proximal factors that may influence happiness, which in this research is a morally challenging situation. Individuals participate in an experiment in which doing well on a task increases their chances of earning money in a lottery, but they learn that there is a way to cheat to get ahead. Some cheat and some do not. For each group, relying on the identity process in sociology (Stets and Burke 2009), we measure participants' moral identity and examine whether comparisons of self versus others' views along the moral dimension influences happiness in this situation. A

\footnotetext{
${ }^{2}$ The social comparison process also has been used in sociology to understand, for example, how income and happiness are related (Schnittker 2008a).

${ }^{3}$ An upward comparison does not always decrease happiness and a downward comparison does not always increase happiness. It depends, for example, on the targets of one's comparison (Buunk, Collins, Taylor, VanYperen, and Dakoff 1990), and the individual characteristics of the person making the comparison (Wheeler 2000). For example, a comparison to a similar other can produce identification, with a downward comparison leading to negative feelings (fear) that one could experience a similar plight, while a downward comparison to a dissimilar other can lead to a contrast effect and induce pride that another's plight will never happen to oneself (Smith 2000). Regarding individual characteristics, compared to those with low self-esteem, those with high self-esteem make more downward comparisons, and compared to those with a stable self-esteem, those with an unstable self-esteem make more upward comparisons (Wheeler 2000). Thus, the question is not whether social comparisons influence happiness, but when and what kinds of comparisons produce this effect (Diener, Suh, Lucas, and Smith 1999).
} 
discrepancy between self-other views may reduce happiness because individuals' identities are not being verified. More generally, we study the social comparison process that exists within identity theory (Stets and Burke 2014b), which we then apply to an analysis of the moral identity in this study to determine its influence on situational happiness.

We also examine macro forces or distal factors that may influence happiness. We examine one's position in the social structure in terms of gender and race, and human capital that individuals may possess in the situation. Human capital is individuals' investment in skills, knowledge, and experience that increases their worth as producers and advances them materially (Becker 1964). In this research, human capital is assessed in terms of people's skills/ability to successfully carry out the task in this study. Clearly, if people have the ability to perform well on the task, there is no need to behave dishonestly, and thus self-other views along the moral dimension may not be pertinent. Thus, we explore whether distal factors play a more significant role in influencing happiness when moral issues are not as salient for individuals.

\section{Theory}

\section{Macro Forces}

Early studies in sociology revealed that those higher in the status hierarchy along a variety of dimensions such as race, education, income, and marital status were happier than those lower in the status hierarchy (Davis 1984). The exception to this was gender with women reporting greater overall happiness than men. More recent evidence reveals that inequality in overall happiness has fallen significantly since the 1970s, particularly with respect to gender and race (Stevenson and Wolfers 2008; Stevenson and Wolfers 2009; Yang 2008), although this pattern does not apply to income; those earning more remain happier than those earning less (Stevenson and Wolfers 2013). While these effects occur for reports of overall happiness, we examine 
whether gender and race influence reports of happinees in this study, recognizing that people's general evaluation of their life as happy may be different than their reports of happiness in a specific situation. ${ }^{4}$

We also examine a form of human capital that participants in the social structure may possess that may facilitate both their success in the current study and their feeling of happiness. In human capital theory, investing and acquiring capital is open to anyone in the social structure.

Education, training, migration to places where benefits are higher, and so forth, all advance power and profit for people. Those who have the skills to accomplish the goal in the current study, that is, performing well on the task, may report greater happiness than those less skilled. Those less skilled at the task are at a disadvantage in this study (and perhaps more generally) in the same way that those with a lower position in the social structure are disadvantaged, which may lead to reports of less happiness. However, skill is not the only factor that can help participants do well on the task. Participants in the study discover that they can use an illegitimate means - cheating - to score highly, which challenges one's morals.

This situation is analogous to what the disadvantaged experience in the social structure as outlined in strain theory (Merton 1957). When people do not have an acceptable avenue to achieve valued goals because they lack the opportunities and advantages that others enjoy, they may rely on unacceptable methods to obtain these goals. Compared to those with high task ability, if those with low task ability in this study are more inclined to cheat, this may raise issues about one's identity as a moral person. In turn, verifying one's moral identity may become relevant to feelings of happiness in the situation. In contrast, high task ability is unlikely to encourage one to cheat, thus circumventing issues about one's identity as a moral person.

\footnotetext{
${ }^{4}$ We do not examine income because study participants are full-time college students rather than workers in the labor force.
} 
Consequently, rather than the moral identity having an influence on feelings of happiness, it may be human capital (here, task ability) as well as their position in the status hierarchy (here, their gender and race) that is associated with their happiness. We examine this.

\section{Micro Forces}

In identity theory, an identity is the set of meanings (characteristics or descriptors) that define who one is as a person, in a role, or as a member of a group/category (Burke and Stets 2009). Identity verification is a process of individuals' comparing their identity standard (their selfmeanings) with how they think others see them in the situation (reflected appraisals). For example, if individuals have meanings of being "honest" and "fair" when they think about themselves in terms of their moral identity, and they think that others see them as "honest" and "fair" when a situation activates the moral identity and calls forth behaving in a moral manner, then this comparison results in a correspondence between the identity standard (self-views) and the reflected appraisals (others' views). This correspondence is identity verification, and in identity theory, verification is associated with positive emotions such as happiness. Nonverification is associated with negative emotions. The positive emotional outcomes tied to identity verification are consistent with the idea in psychology that people feel happy when they experience goal attainment (Wrosch, Miller, Scheier, and de Pontet 2007). Goal attainment in identity theory is identity verification, comparing one's identity standard with the reflected appraisals is central in this process.

Another important comparison for identities is the degree to which meanings in one's identity standard are relevant to the meanings in the situation (Stets and Burke 2014b). An identity is activated in a situation when the dimensions of meaning that define the self, for example, being fair, are also relevant in the situation. Essentially, the meanings in the situation 
become relevant or potent for an identity that contains similar meanings to be activated (Stets and Burke 2014a; Stets and Carter 2012). It is this relevant identity in the situation that is important both for the identity verification process and for resulting feelings of happiness. For example, if the meanings in the situation call forth moral behavior such as helping an elderly person cross an intersection, the moral identity will be activated to guide the prosocial act. If the person then thinks that given his/her helpful act that others see him/her as moral in a way that matches his/her self-views as a moral person, identity verification has occurred and the individual will feel good. Thus, without a match between situation meanings and identity meanings, a comparison between self-views and others' views of an identity will not occur. The verification or non-verification of an irrelevant identity will be inconsequential to feelings of happiness in the situation because the comparison process is not activated. ${ }^{5}$

Given the above two comparison processes, we think that the moral identity will get activated in our study when individuals cheat. Behaving dishonestly calls forth issues surrounding oneself as a moral person, and the verification of the moral identity may be important to feeling happy in the situation. The moral identity is a person identity because it references the meaning that characterize the individual as a unique individual (Burke and Stets 2009). In this study, another identity - the identity of being a member of a group - might also influence feeling happy, as we explain.

\footnotetext{
${ }^{5}$ While situational meanings can "activate" a particular identity that corresponds to the situational meanings, it is also possible for people to call up or activate a salient identity regardless of the situational meanings. In this situation, the individual would construct meanings in the situation that would correspond to the meanings in the salient identity. For example, if the parent identity is particularly salient for individuals, they may call up this identity at work and construct meanings that correspond to it such as talking about their children to their co-workers, showing pictures of their children, texting their children at work, bringing their children to work and so forth. Identity verification of the parent identity would then have consequences of feeling happy in the situation.
} 
The study design randomizes individuals into two conditions: one in which they complete the task as individuals, and one in which they complete the task as a member of three-person group. In the group condition, individuals learn that they will be competing against another three-person group. The group that scores higher on the task will result in each group member increasing their chances of winning money in the lottery. Consequently, some are working to satisfy their own interests as they work alone, while others are working to satisfy the group's interest as they compete with another group on the task.

Identifying with one's group and the positive feelings associated with it may be alternative meanings to the meaning of being moral in the situation. In our study, membership in a group is based on the "minimal group" experiments in social identity theory in which categorizing a person as a member of a group is sufficient for the person to identify with that group (Turner, Hogg, Oakes, Reicher, and Wetherell 1987). Further, naming a person as a member of one group as opposed to another is sufficient for the person to identify and positively evaluate the group assigned to him/her (the in-group) and dis-identify and negatively evaluate the other group (the out-group). A "we" or "us" develops toward the in-group and a "them" develops toward the outgroup. The positive evaluation associated with an arbitrary group is rooted in individuals' desire for a positive social identity (Tajfel and Turner 1979). Once individuals identify with a group, they should behave in ways that benefit their group as well as themselves. This is the process of depersonalization that occurs when individuals identify with a group. Rather than seeing themselves as unique individuals, they see themselves as part of something larger than themselves. It is not that they lose a sense of who they are as individuals; the group identity simply becomes more important. 
If multiple identities potentially are activated in a situation, the identity which has meanings that best correspond to the meanings in the situation should be the identity that is most likely to influence feelings of happiness. Essentially, the best fitting or most relevant identity in the situation should matter the most in influencing feelings of happiness. When individuals cheat, we think that micro processes associated with one's moral identity will be more relevant than one's group identity in influencing happiness. Issues of dishonesty are raised, making the moral identity more potent in the situation. When individuals do not cheat, processes associated with membership in a group may be more important than one's moral identity in influencing happiness.

Taken together, we study how distal as well as proximal factors shape happiness on a task where individuals seek to do their best in order to increase their chances of winning money in a lottery. Some people work on this task by themselves while others work on the task in a group. All individuals learn that there is a way to cheat to perform better. At issue is how the identity process as well as one's position in the social structure influences reports of happiness following the task.

\section{METHOD}

\section{Sample and Study Overview}

Students were recruited from undergraduate classes at a large southwestern university. They were given extra credit for participating in a two-part study as well as given the chance to be one of five students who would earn $\$ 50$ in a $\$ 250$ lottery. Of the 284 participants completing both the survey and laboratory task, 93 individuals were in the alone condition, and 191 were in the group condition. In the group condition, individuals were randomly assigned to two other group members who were either low status (high school students) or high status (graduate students). 
We examined the effect of low/high status on whether participants cheated on the task as well as feelings of happiness, and we found no significant effects. ${ }^{6}$ Therefore, we pooled the participants in both groups for this analysis.

More women (67\%) than men (33\%) participated in this study. This gender distribution is different from the university from which this sample is drawn (52\% female and $48 \%$ male $)$, but it is characteristic of the sociology classes from which the sample is drawn. Besides gender, other characteristics of our sample are similar to the university population. For example, the average age of this sample is 20 , which is similar to the average age of the university (21). The sample was also ethnically diverse (30\% Asian, 28\% Latino, 13\% White, $8 \%$ Black, 21\% Multi-racial or other) as is the university where the data was collected (40\% Asian, 29\% Latino, 17\% White, $8 \%$ Black, and $6 \%$ other).

In Part 1 of the study, participants were administered a survey that captured their demographic profile as outlined above and their social psychological profile such as their moral identity. In Part 2, several weeks later, they participated in a laboratory study involving a decision-making task: NASA's Lost on the Moon (LOTM) activity. ${ }^{7}$ This task has been commonly used in prior research (Shelly and Troyer 2001; Shelly, Troyer, Munroe, and Burger 1999; Shelly and Webster 1997). The activity included an opportunity to cheat, without clear detection, to improve their performance. ${ }^{8}$ All participants were told that the better they did on the LOTM, the more tickets they would receive toward the lottery, thereby increasing their chances

\footnotetext{
${ }^{6}$ These results are available upon request.

${ }^{7}$ Having a delay of several weeks between Part 1 and Part 2 was implemented to reduce the likelihood that participants would make a connection between the two parts.

${ }^{8}$ Participants were not told whether their cheating could be detected. When people encounter opportunities to cheat in everyday life, it is ambiguous whether their cheating will be detected. Therefore, we left this ambiguous in this study.
} 
of winning one of the $\$ 50$ prizes. This provided an incentive to cheat. Participants completed the task either alone (individual condition) or with two other individuals as a group (group condition). A measure of happiness was obtained prior to the task and after completing the task.

\section{Study Procedures}

Several weeks following completion of the survey portion of the study, participants arrived at the laboratory for the second part of the study. They were greeted by a lab assistant and taken into a separate room that had a computer workstation. They were told that they would be completing NASA's Lost on the Moon activity. Participants were to imagine a situation where, as a member of a space expedition, their space ship crashes on the moon, leaving them stranded from a rendezvous point with a mother ship 200 miles away. They were told that when they landed, everything was damaged except for 15 items. They were informed that their crew's survival depended on reaching the rendezvous point, but only the most crucial of the 15 items were to be selected to make the 200-mile journey. There is a logical "correct" sequence to ranking these items, as some are more crucial to survival than others (for example, oxygen is most crucial and should be selected over a box of matches, which are useless).

To pick the most important items, participants were given 12 questions over the computer. Each question presented four choices, and participants were to select the most critical one out of the four presented that they thought was needed for the 200-mile journey. As participants moved through each question, they were to select the most crucial item out of the list of four until they completed the 12 questions. ${ }^{9}$

\footnotetext{
${ }^{9}$ For example, for the first question, four of the 15 items were presented on the screen. One was the most critical, and the other three were randomly selected and listed from the remaining 14 items. For the second question, a slightly different list of items was listed (sometimes filler items were repeated), but one item was the second best item needed for the journey. Questions three through twelve were structured in the same way such that participants were ranking the items according to the most important and correct
} 
Before participants started the task, they were told five students would each earn $\$ 50$ in a $\$ 250$ lottery. The participants also were told that they would receive five tickets from the research scientists sponsoring the current study to show their appreciation for the participants' involvement in the study. However, lottery tickets would be taken away from them depending upon their final score on the LOTM activity. If they did not score above average on the task compared to other participants (individual condition) or if their group did not score more than a group they were competing against (group condition), two tickets would be taken away from each of them. If they did not score at least average compared to all others (individual condition) or at least tie the other group's combined score (group condition), two more tickets would be taken away from each of them. ${ }^{10}$ It was in the interest of participants to maximize their score, thereby providing an incentive to cheat in order to do well.

In the group condition, participants were told that they would be working on the LOTM activity with two other individuals. ${ }^{11}$ There were two groups: "Lunar Expedition Alpha" and "Command Squadron Omega." Participants were always assigned to the "Lunar Expedition Alpha" group. They were informed that their two other group members were at other computer stations in the lab, and they would be interacting with them over the computer. The opposing three-person group would be completing LOTM at the same time, but in another location.

sequence. Participants did not rank the remaining three (least important items) that would complete the 15-item list.

${ }^{10}$ Removing a resource has been found to have a stronger effect on motivating non-normative behavior than adding a resource (Kahneman and Tversky 1979).

11 These two group members were computer generated. Participants never knew that "Command Squadron Omega" did not exist because they never had the opportunity to interact with them. A manipulation check was included in the final questions before the debriefing asking participants whether they did or did not believe they were participating in a real group. All participants responded that they believed they were in a real group. 
Before leaving the participant at their computer station, the lab assistant indicated that the computer needed to be checked to make sure LOTM was set up and working properly. In reality, there was nothing wrong with the computer; this simply gave the assistant an opportunity to demonstrate how an answer could be changed (how participants could cheat). There were "practice questions" that the participants had to first answer before beginning the task, so the assistant worked alongside the participant to check that everything was working properly. The assistant read the first question aloud, and then deliberately gave the participant a wrong answer to enter. When the next screen appeared, it indicated the participant's response and the correct response. The assistant asked the participants to "play along" and indicated that s/he was going to try some things. The assistant then used the "ESC" key to go back to the screen which contained the original question. The assistant changed the participant's answer to the correct answer, and then moved forward to see whether the program would give the participant credit for the correct answer. The assistant acted shocked to have discovered that it did and told the participant not to use the "ESC" key to change his/her answers.

The assistant went through two more "practice questions" with the participant. In one of them, the "ESC" key was used to change an answer again. The assistant indicated s/he was using this key again to make sure it would enable one to return to the previous screen to change an answer. After the second use of the "ESC" key, the assistant acknowledged that this key could be used to change one's answers, but reiterated that this should not be done. ${ }^{12}$

Following this, the lab assistant completed some final tasks. Among them, they provided participants with a brief quiz that asked them to identify how many tickets they would lose if they did not score above average or average compared to their counterparts. If they did not

\footnotetext{
12 This cheating protocol is consistent with that used by others (Kalkhoff and Willer 2008; Stets and Carter 2011). A post-test indicated that none of the participants identified cheating as the purpose of the study.
} 
answer each question correctly, the assistant reviewed the ticket situation again, and participants were given another quiz to ensure they understood the payoff structure. After answering any questions that the participants had, the assistant left the room for the participants to begin the task.

After the participants had finished the LOTM task, they answered a brief survey. In the survey, they were to report how happy they currently were feeling. Then, they were debriefed. At the debriefing, they were informed that their test score would not be compared with all other participant scores (individual condition) or with the group who they were competing against (group condition). They would not earn additional tickets for the lottery. Instead, everyone earned one lottery ticket in exchange for their participation in this study.

\section{Measures}

The Moral Identity. In the survey administered several weeks before the laboratory study, respondents were given a list of 12 bipolar characteristics that operationalized the moral identity (Stets and Burke 2014a; Stets and Carter 2011;2012). The 12 characteristics included being honest/dishonest, caring/uncaring, unkind/kind, unfair/fair, helpful/not helpful, stingy/generous, compassionate/hardhearted, untruthful/truthful, not hardworking/hardworking, friendly/unfriendly, selfish/selfless, and principled/unprincipled. ${ }^{13}$ Individuals were to think about how they saw themselves with respect to each characteristic and select their location on the

${ }^{13}$ Consistent with prior research, these items operationalize two dimensions of the moral identity: care and justice (Stets and Carter 2011; 2012). Justice encompasses aspects of morality such as fairness, honesty, and integrity; care emphasizes compassion and kindness. While our focus in this study is not on morality per se but on the verification of an identity, we do recognize that the spectrum of morality could include a broader set of dimensions such as harm/care, fairness/reciprocity, in-group/loyalty, authority/respect, and purity/sanctity (Haidt and Graham 2009; Haidt and Kesebir 2010). The focus on justice and care is consistent with Western conceptions of morality that tend to value protecting individuals' welfare and autonomy (Haidt and Graham 2009). Beyond western cultures, however, all cultures appear to promote morals of being just and caring (Hauser 2006). 
bipolar dimension. The value of 1 reflected agreement with one bipolar characteristic, the value of 5 reflected agreement with the other bipolar characteristic, and 3 placed individuals between the two characteristics. A factor analysis revealed a single factor with an omega reliability of .91. The items were then aligned and summed so that a high score reflects a high level of morality. The scale was then standardized (mean of 0 and variance of 1$).{ }^{14}$

Reflected Appraisals. In the brief survey following the LOTM task, participants were asked to report how they thought others would see them on a variety of dimensions including being likeable, intelligent, moral, dominant, spiritual, attractive, reliable, loving and competitive. We were interested in how they thought others would see them as a moral person. The other items were filler items. Responses to the "moral" item ranged from "Not at all" (coded 0) to "Very much so" (coded 6). The reflected appraisals item for the moral identity was standardized.

Moral Identity Discrepancy (Non-Verification). Two aspects of the moral identity discrepancy were calculated: a linear term and a squared term. The linear discrepancy is the reflected appraisals measure minus the moral identity standard measure. A positive value means that individuals think that others see them more positively than how they see themselves along the moral dimension; a negative value means that they think that others see them more negatively than how they see themselves along the moral dimension, while a 0 means that the individual thinks others see them as they see themselves. The squared discrepancy is the square of the linear discrepancy. A higher value represents a larger identity difference between the identity meanings and reflected appraisals in either the positive or negative direction. We are particularly interested in the squared discrepancy measure. According to identity theory, a discrepancy in either a positive or negative direction is a non-verifying state, and a non-verifying

\footnotetext{
${ }^{14}$ A t-test showed no significant difference in participants' moral identity standard between conditions (individual vs. group) $t=-.62$, df (282), ns.
} 
state generates less positive emotion (Burke and Stets 2009). Both the linear and the squared discrepancy measures were standardized.

Happiness. Happiness is measured at two different time points: before the participants begin the LOTM activity, and following the LOTM activity. Since one's feelings can carry over from one situation to the next, we control for feelings of happiness prior to the study. This assures us that the happiness we measure after the study is due to what occurred during the study. At both time points, individuals were asked to select a number that best represented how happy they were currently feeling. Response categories ranged from "Not at all" (coded 0) to "Very Intense" (coded 10). To reiterate, rather than studying people's overall happiness with their life (subjective well-being) (Diener 2008; Veenhoven 2008), we are examining happiness in the immediate situation.

Cheating. There were two measures of cheating: whether individuals cheat, and the frequency of cheating. To determine if participants cheated, the computer program created a variable indicating whether individuals used the "ESC" key to go back and change their answer from their original answer. ${ }^{15}$ If individuals changed any of their answers using this method, cheat is coded 1 ; otherwise it is coded 0 . Cheating frequency represents the number of times individuals changed their answers across the 12 questions.

Task Ability. This represents the number of correct questions participants completed without cheating. It is a resource associated with human capital because it operationalizes participants' knowledge or skill level associated with the NASA activity. The measure was created by subtracting the number of questions in which participants cheated (using the "ESC" key to

\footnotetext{
${ }^{15}$ Participants were not aware their behavior would be tracked in this manner.
} 
change an incorrect answer to a correct answer) from the total questions answered correctly. The higher the value, the more questions were answered correctly without cheating.

Group. Those completing the task alone were coded 0, and those completing the task in a group were coded 1.

Gender. Females were coded 0 and males were coded 1.

Race/Ethnicity. Race/ethnicity included: white, latino, asian, black, and other. Members of each group were coded 1 for their group and 0 otherwise. White was the omitted category.

\section{Analysis}

To study people's feeling of happiness following a morally challenging situation, several preliminary analyses are carried out. We are interested in what influences happiness prior to the task commencing. Research suggests that one's position in the social structure (here, gender and race) as well as human capital, operationalized as task ability, should be important. We also are interested in what predicts cheating. If, as we suspect, the moral identity is more likely to get activated following cheating, then of interest is what initially produces cheating. We examine whether individuals cheated at all as well as the frequency of cheating. We anticipate that when human capital is in short supply, individuals will resort to cheating to increase their chances of winning money in the lottery.

To study the factors associated with happiness, we analyze whether the results are different when individuals carry out the task by themselves compared to in a group. For group members, if the group identity gets activated, it may set in motion different dynamics that may influence happiness compared to when they are acting alone. For example, if individuals cheat when they are acting for the group, this may not affect their current happiness as much as it would for those acting alone. Cheating may be perceived as in the service of helping the group rather than 
oneself. Consequently, we used structural equation modeling, which allows for a test of group differences (individual vs. group condition). We estimated three models. In our first model, we estimated the effects of our independent variables on happiness for those in the combined individual and group conditions. A test of differences in the coefficients for the two conditions indicated that only the frequency of cheating effect was significantly different. Thus, we allowed this effect to vary, and we constrained all other effects to be equal.

In the second and third models, we ran an analysis on two separate populations: those who did not cheat and those who cheated. For those who did not cheat, none of the effects were significantly different for those completing the task by themselves or in a group. Thus, all of these effects were constrained to be equal. For those who cheated, there were two group differences between the alone and group conditions. The effect of the frequency of cheating and the effect of the linear moral identity discrepancy were significantly different. Therefore, we allowed these coefficients to vary and all other coefficients we constrained to be equal.

\section{RESULTS}

Table 1 presents the mean and standard deviations for the variables in the analyses. Participants scored an average of about 8 points out of 11 points; no one received a perfect score of 12 points. If people were not taking the study seriously, the average number of points earned likely would have been low. Thus, the relatively high number of average points earned suggests participants took the study seriously and made an effort to do well. The squared moral identity discrepancy variable is positively skewed with the majority of cases falling at zero. Thus, most individuals had their moral identities verified in this situation. 
Table 1. Means and Standard Deviations of Variables $(N=284)$

\begin{tabular}{lcccc}
\hline Variables & Mean & SD & Min & Max \\
\hline Happiness & 5.74 & 1.94 & 0 & 9 \\
Happiness $_{\text {t-1 }}$ & 5.58 & 1.80 & 0 & 9 \\
Task Ability & 7.87 & 2.03 & 0 & 11 \\
Cheat & .27 & .45 & 0 & 1 \\
Cheating Frequency & .63 & 1.36 & 0 & 8 \\
Moral Identity $_{\text {Linear MI discrepancy }}{ }^{\mathrm{a}}$ & 0 & 1.00 & -3.05 & 1.76 \\
Squared MI discrepancy $_{\text {Gender }}$ & 0 & 1.00 & -3.07 & 2.45 \\
White & 0 & 1.00 & -.71 & 5.99 \\
Latino & .33 & .47 & 0 & 1 \\
Asian & .13 & .33 & 0 & 1 \\
Black & .28 & .45 & 0 & 1 \\
Other & .29 & .45 & 0 & 1 \\
Group & .08 & .27 & 0 & 1 \\
a MI Moral Identity & .22 & .41 & 0 & 1 \\
\hline
\end{tabular}

${ }^{\mathrm{a}} \mathrm{MI}=$ Moral Identity

Table 2 presents the correlations among all the variables. Not surprisingly, the level of happiness prior to the task is correctly with happiness following task completion $(r=.50, p<$. 05). A higher moral identity is associated with higher happiness both prior to the task $(r=.18, p$ $<.05)$ and following the task $(r=.20, p<.05)$. Surprisingly, blacks report higher rather than lower happiness compared to whites $(r=.21, p<.05)$. Additionally, there are decreases in happiness as the moral identity discrepancy increases $(r=-.15, p<.05)$. The frequency of cheating and task ability are significantly correlated $(r=-.35 p<.05)$. Those who perform better on the task are less likely to cheat. 
Table 2. Correlations among Variables $(N=284)$

\begin{tabular}{|c|c|c|c|c|c|c|c|c|c|c|c|c|c|c|c|}
\hline Variables & $(1)$ & $(2)$ & (3) & (4) & $(5)$ & (6) & $(7)$ & $(8)$ & $(9)$ & $(10)$ & $(11)$ & $(12)$ & $(13)$ & $(14)$ & $(15)$ \\
\hline (1) Happiness & 1.00 & & & & & & & & & & & & & & \\
\hline (2) Happiness $\mathrm{t}_{\mathrm{t}-1}$ & $.50^{*}$ & 1.00 & & & & & & & & & & & & & \\
\hline (3) Task Ability & .08 & .05 & 1.00 & & & & & & & & & & & & \\
\hline (4) Cheat & .10 & .01 & $-.19 *$ & 1.00 & & & & & & & & & & & \\
\hline (5) Cheating Freq. & .00 & .05 & $-.35 *$ & $.76 *$ & 1.00 & & & & & & & & & & \\
\hline (6) Moral Identity & $.20 *$ & $.18^{*}$ & .05 & -.09 & -.06 & 1.00 & & & & & & & & & \\
\hline (7) Linear MID & .04 & .03 & .08 & .05 & -.03 & $-.63 *$ & 1.00 & & & & & & & & \\
\hline (8) Squared MID & $-.15^{*}$ & -.06 & -.11 & -.00 & .09 & $-.15 *$ & $-.16^{*}$ & 1.00 & & & & & & & \\
\hline (9) Gender & .01 & -.06 & -.01 & -.02 & -.04 & $-.28 *$ & $.22 *$ & .07 & 1.00 & & & & & & \\
\hline (10) White & .04 & .06 & .05 & -.02 & -.05 & -.03 & .00 & .01 & .00 & 1.00 & & & & & \\
\hline (11) Latino & -.06 & -.10 & -.01 & -.07 & .00 & .11 & -.01 & .05 & $-.15^{*}$ & $-.24 *$ & 1.00 & & & & \\
\hline (12) Asian & -.09 & $-.14 *$ & -.05 & .08 & .06 & $-.21 *$ & .10 & .03 & $.21 *$ & $-.25 *$ & $-.40 *$ & 1.00 & & & \\
\hline (13) Black & $.21 *$ & .10 & -.08 & .02 & .01 & .07 & -.01 & -.09 & $-.15^{*}$ & -.11 & $-.19 *$ & $-.19 *$ & 1.00 & & \\
\hline (14) Other & .00 & $.15^{*}$ & .08 & -.02 & -.04 & .09 & -.08 & -.04 & .03 & -.10 & $-.33 *$ & $-.34 *$ & $-.16^{*}$ & 1.00 & \\
\hline (15) Group & .09 & -.02 & .03 & .09 & .04 & .04 & -.04 & .00 & .01 & -.04 & -.03 & .05 & .02 & -.01 & 1.00 \\
\hline
\end{tabular}

$* p<05$.

MID = Moral Identity Discrepancy 
Table 3 shows the factors affecting the likelihood of cheating, and if participants cheat, how much they cheat. None of the factors except the human capital factor of ability influences cheating or the frequency of cheating. For every correct answer that participants achieve, the probability of cheating is reduced by almost 20 percent (odds ratio $=.81, p<.05$ ). Additionally, task ability negatively influences the frequency of cheating $(\beta=-.35, p<.05)$. In general, cheating is a function of people seeing that they are not performing well, so they cheat to counteract their poor performance and obtain what they desire: a greater chance of winning money in the lottery. ${ }^{16}$

\begin{tabular}{|c|c|c|}
\hline $\begin{array}{l}\text { Independent } \\
\text { Variables }\end{array}$ & Cheat & $\begin{array}{l}\text { Cheating } \\
\text { Frequency }\end{array}$ \\
\hline Moral Identity & .81 & -.07 \\
\hline Task Ability & $.81^{*}$ & $-.35 *$ \\
\hline Happiness ${ }_{t-1}$ & 1.05 & .08 \\
\hline Group & 1.63 & .05 \\
\hline Gender & .73 & -.06 \\
\hline Latino & .83 & .06 \\
\hline Asian & 1.30 & .08 \\
\hline Black & 1.04 & .01 \\
\hline Other & 1.07 & .03 \\
\hline $\begin{array}{l}\chi^{2} \\
R^{2}\end{array}$ & $16.95^{*}$ & $.14^{*}$ \\
\hline
\end{tabular}

Table 4 reveals the factors associated with happiness prior to the task and following the task. In the first column, prior happiness is largely a function of a micro process: one's identity. Those with a higher moral identity are happier compared to those with a lower moral identity $(\beta=.16$,

\footnotetext{
${ }^{16}$ There is only a tendency for a high moral identity to be associated with a reduction in cheating $(p<.10)$.
} 
$p<.05)$. None of the macro forces are associated with happiness. One's position in the status hierarchy and greater skills has no bearing on one's current happiness. ${ }^{17}$

Column two displays the effects for happiness following the task for everyone. The model fits the data well $\left(\chi^{2}=6.51, d f=9, p=0.69, \mathrm{TLI}=1.06, \mathrm{CFI}=1.00, \mathrm{RMSEA}=.00\right)$. Not surprisingly, happiness prior to the task is positively associated with happiness following the task $(\beta=.51, p<.05)$. The frequency of cheating reduces happiness, but only for those working on the task alone $(\beta=-.19, p<.05)$ compared to those working in a group $(\beta=.09, \mathrm{~ns})$. When individuals cheat in the group, they may feel justified for behaving dishonestly because they are helping their group as it competes against the rival group. Thus, when the social identity is activated, people may not feel that they are acting badly, thereby being emotionally unaffected.

The results also show a significant effect of a discrepancy in the moral identity. Individuals experience a reduction in happiness when they think that people view them as more moral than how they view themselves or less moral than how they view themselves $(\beta=-.11, p<.05)$. Since the effect occurs both for individuals who completed the task alone and those who completed it in a group, it suggests that the moral identity is relevant even when one's social identity is activated. Interestingly, having human capital resources (task ability) does not influence happiness. Finally, the only social structural factor that influences happiness is one's race. However, rather than blacks reporting lower happiness compared to whites, they report higher happiness.

\footnotetext{
${ }^{17}$ Even when the moral identity was omitted from the equation, social structural factors still were not associated with happiness. These results are available upon request.
} 
Column three in Table 4 reveals what relates to happiness for those who do not cheat during the task. The model shows a good fit $\left(\chi^{2}=9.02, d f=9, p=0.44, \mathrm{TLI}=1.00, \mathrm{CFI}=1.00\right.$, RMSEA $=.01)$. Again, happiness prior to the task positively predicts happiness following the task $(\beta=.60, p<.05)$. Neither the linear nor squared moral identity discrepancy influences happiness. This model also shows there are no individual or group differences for those that did not cheat. Finally, while the social factor of task ability does not influence happiness, one's position in the social structure does. However, rather than women and whites reporting greater happiness as prior research has found, the results show that it is men and blacks who report greater happiness following the task.

Table 4. Standardized Effects on Happiness $(N=284)$

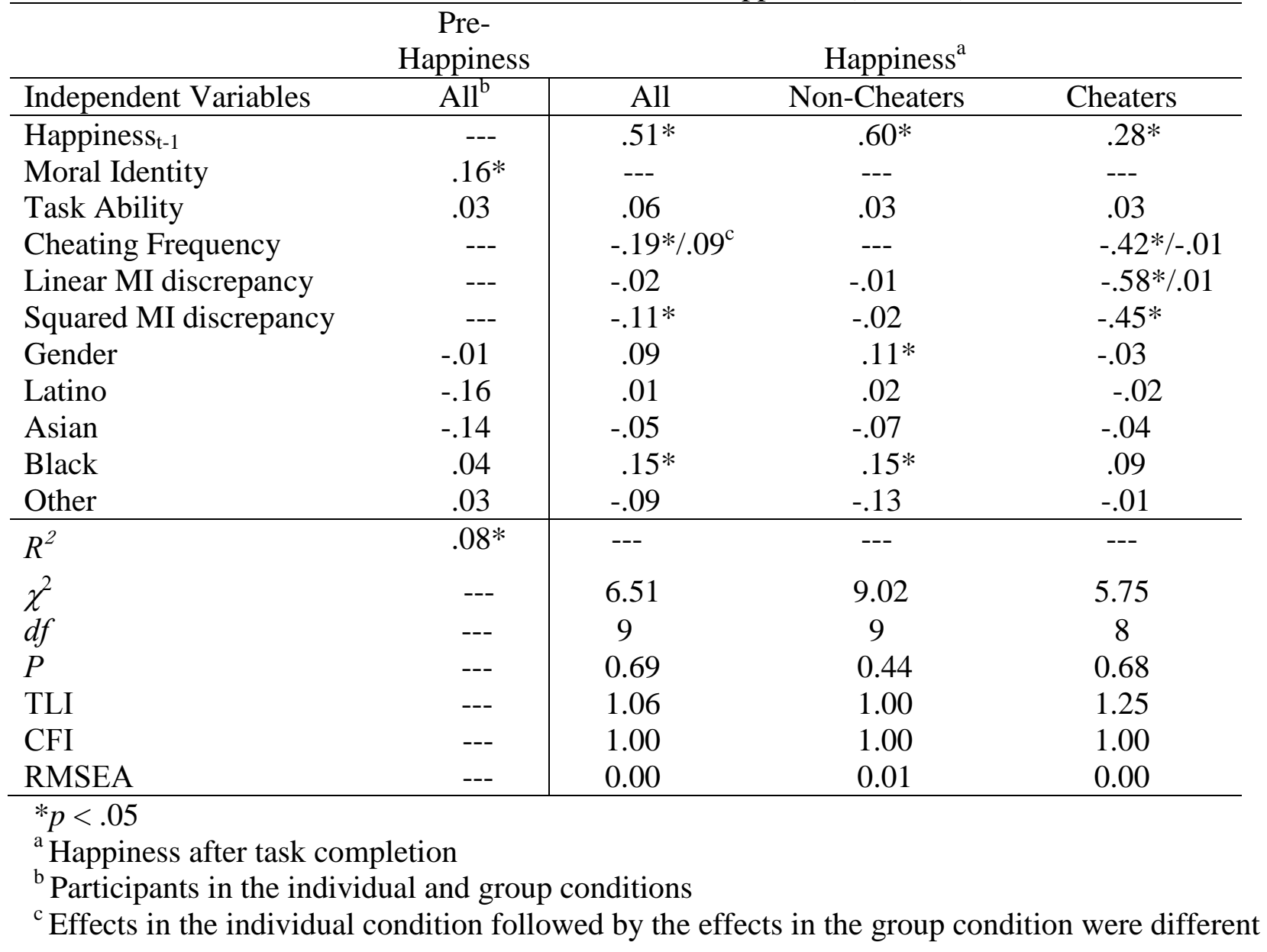


The final column in Table 4 reveals what influences happiness for those who cheat during the task. ${ }^{18}$ The model fits the data well $\left(\chi^{2}=5.75, d f=8, p=0.44\right.$, TLI $=1.25$, CFI $=1.00$, RMSEA $=.00$ ). While happiness prior to the task positively influences happiness following the task ( $\beta=$ $.28, p<.05)$, it is not the strongest factor influencing happiness. In fact, this effect is significantly reduced in this model compared with the effect for those who do not cheat. Apparently prior happiness is disrupted for people who cheat. As in the first model, the more frequently participants cheat, the greater their unhappiness, but this occurs only for those working alone $(\beta=-.42, p<.05)$ compared to those working as a group $(\beta=-.01, \mathrm{~ns}) .{ }^{19}$ Unlike the model for non-cheaters, none of the social factors influence happiness. What does have an impact is the identity process. While the linear moral identity discrepancy has a significant effect only in the individual condition $(\beta=-.58, p<.05)$, the squared moral identity discrepancy has an effect on happiness in both conditions $(\beta=-.45, p<.05)$.

The effect of the linear moral identity discrepancy $(\beta=-.58, p<.05)$ must be interpreted in light of the effect of the squared moral identity discrepancy, which indicates that when those who cheat think that others see them as either more moral or less moral than how they see themselves, they report reduced happiness ( $\beta=-.45, p<.05$ ). Essentially, there are two components to this effect: the linear and squared discrepancies. When we combine the two effects to examine the overall effect of discrepancy, we see that the combined effect of both is an inverted U-shaped

\footnotetext{
${ }^{18}$ Individuals could use the escape key to go back and identify the correct answer, and then proceed without changing their response to the correct answer. We examined the effect of using the escape key to simply identify the correct answer and not change one's response to the correct answer. The moral identity was not significantly related to using the ESC key for this purpose. Additionally, using the ESC key in this manner did not influence happiness. These results are available upon request.

${ }^{19}$ We explored whether cheating that occurred later in the task would be more likely to influence happiness than cheating that occurred early in the task. The timing of the cheating did not significantly influence happiness. These results are available upon request.
} 
curve that is shifted slightly to the left on the x-axis as shown by the bolded line in Figure 1 . The linear effect makes people feel happy for a small amount of under-evaluation, but beyond this small amount because of the squared effect, people are less happy. A small amount of underevaluation feels better perhaps because an under-evaluation is consistent with the recent cheating behavior. However, this effect of the linear term only occurs in the individual condition. People may not feel happy when they think they are being under-evaluated in the group because cheating may be intended to help the group and not be viewed as immoral. Overall, feelings of happiness are dominated by the squared effect, revealing that a discrepancy in either a positive or negative direction reduces happiness. This is the consistency effect that is expected in identity theory.

Figure 1. Moral Identity Discrepancy on Happiness

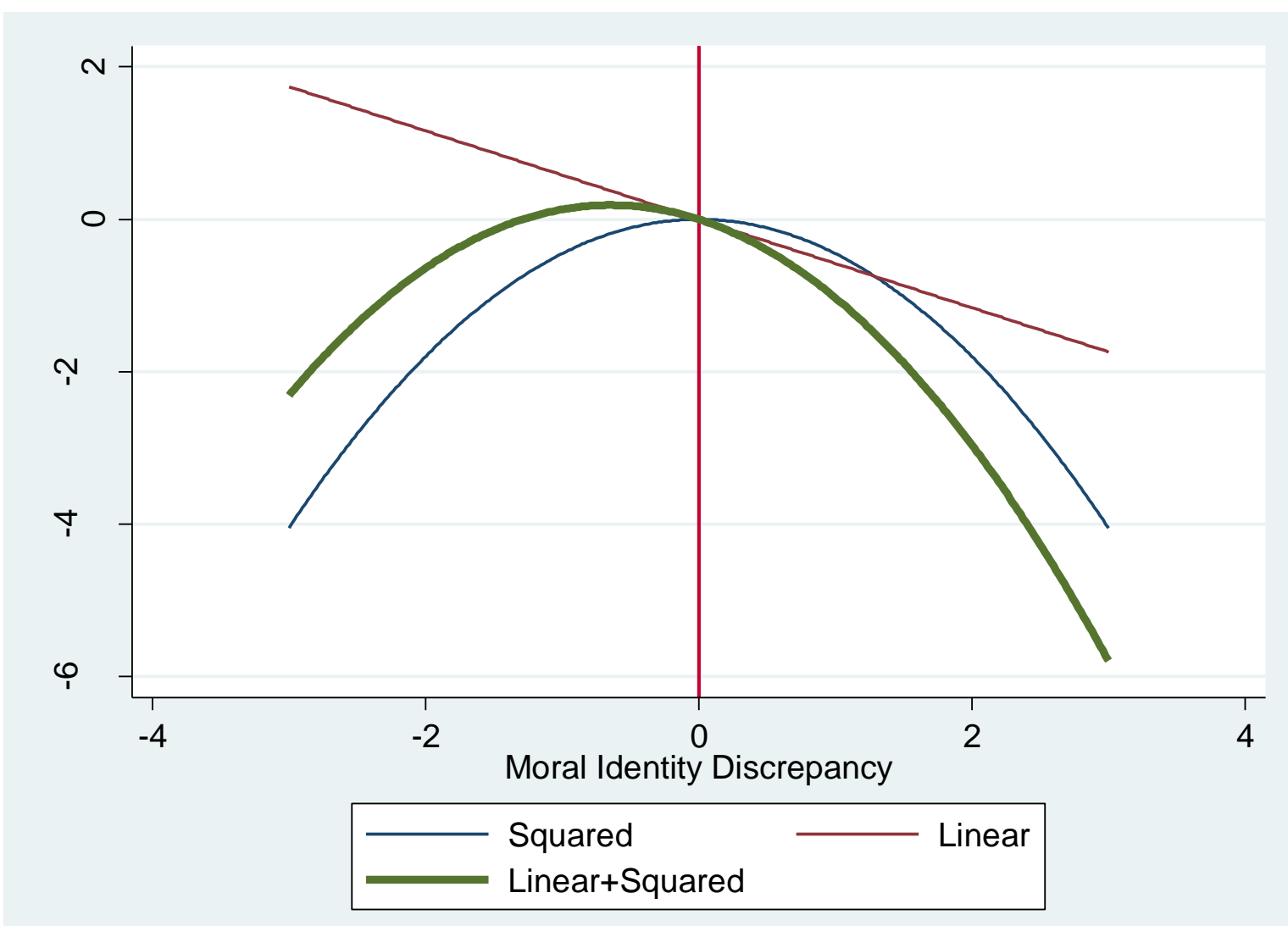


More generally, the results reveal that when individuals do not cheat, the social factors of gender and race play a role in happiness reports. However, when individuals cheat, individual factors are more important than social factors. Cheating appears to activate meanings along the dimension of morality because non-verification of the moral identity reduces happiness for cheaters but not for those who do not cheat. Further, for those who cheat, the moral identity rather than the group identity appears to be more potent or relevant in influencing feelings of happiness because a discrepancy in the moral identity reduces happiness for cheaters, irrespective of completing the task alone or as a group member.

\section{DISCUSSION}

In this research, we were interested in how distal factors at the social structural level as well as proximal factors at the individual level both might play a role in feelings of happiness. The analysis is not with respect to people's evaluation of the overall quality of their lives, but in terms of an immediate situation, specifically a morally challenging situation. We found that different factors influenced happiness depending upon whether individuals behaved dishonestly during the task. Distal factors appeared to be more important in predicting happiness when people behaved honestly, and proximal factors were more important when people were dishonest.

Most individuals in this study did not cheat. Either they believed that cheating was wrong and this deterred them from cheating, or they did not feel compelled to cheat because they could accomplish the task based on their abilities. Indeed, in this study we found that those high in task ability were less likely to cheat. Those that could not answer the questions correctly on their own were more likely to "innovate" or change their answers to get ahead. For the non-cheaters, either they were so bound by their belief that cheating was wrong or so focused on answering the 
questions correctly that behaving dishonestly never emerged. Consequently, they may not have raised the moral dimension of themselves in their minds. If there was not much motivation to think about themselves with respect to their moral identity, then any discrepancy in the moral identity would not influence their happiness in the situation.

What appeared to be most consequential to the happiness of the non-cheaters was their social position in the status hierarchy in terms of their gender and race. However, we found that men and blacks reported greater happiness in the situation than women and whites. Either we cannot extrapolate patterns found about people's general happiness on their lives to their happiness in a specific situation, or inequality in happiness has fallen and perhaps may have inverted. More research on happiness in immediate situations is needed to begin to sort this out.

When we examined the source of individuals' current feelings of happiness before they began the task, we were surprised that none of the structural factors were important as has been found in previous research. This may be due to our restricted sample, which is primarily young, educated, women from a minority group although, as mentioned above, structural factors were associated with feelings of happiness following the task. Interestingly, it was the identity process that was linked to reports of happiness prior to the task with those with a higher moral identity reporting feeling happier than those with a lower moral identity. This suggests that more research is needed on the micro forces that may shape everyday feelings of happiness.

When human capital was in short supply and individuals cheated on the task, while happiness going into the situation carried over to reports of happiness on the task, what we find more compelling was the individual process associated with their identity. When individuals thought that others verified their moral identity in the situation, they were happy. At issue is why the 
verification of the moral identity influenced happiness for those who cheated compared to those who did not cheat. We suggest the following, though further research is needed.

For those who cheated, their counter-normative behavior may grab their attention and carry more informational value for them than the normative behavior of not cheating. The counternormative behavior also may be seen as more intentional compared to unintentional. This is analogous in the literature to action being more informative for individuals compared to nonaction, with non-action having a tendency to be ignored (Fazio, Sherman, and Herr 1982; Ross 1977; Stets 2011). Action also is seen as more intentional or implies more individual responsibility than non-action (Spranca, Minsk, and Baron 1991).

The self is more likely to be implicated in intentional behavior as individuals see themselves as the cause of the outcomes they experience. Further, behaving counter-normatively is more diagnostic as to who one is than behaving normatively. Indeed, normative behavior is less likely to reveal distinctive characteristics about the individuals enacting the behavior because most everyone is acting in the same way. Given that the self is more likely to be implicated in intentional action, coupled with the fact that the action here is counter-normative with meanings of good/bad or right/wrong underlying the behavior, this may be enough to make the moral identity highly relevant for those who cheat. Once any identity becomes highly relevant in a situation, action that follows from it, and the extent to which those actions lead to identity verification, will have an effect on the self, including how people feel.

The above gives us some insight into how macro and micro forces might influence happiness. Identities that get activated in a situation may be more important than one's social structural position in influencing one's immediate happiness. When multiple identities are present in a situation, the identity that is the best fitting or most relevant identity in the situation 
will influence reports of happiness. Given that the situation had stronger meanings of being morally challenging compared to the less pervasive meanings of competition implied by the presence of in-group and out-group members, these stronger moral meanings meant that a discrepancy in their moral identity was especially problematic for how individuals were feeling compared to their group identity.

We point out that the lack of human capital did play an indirect role in reports of happiness because it encouraged cheating so that people could satisfy self-interests, that is, increasing their chances of winning money in the lottery. Thus, those more disadvantaged in the social structure may engage in deviant practices to get what they want, but it may come at a cost of less happiness when others do not verify their moral views of themselves.

There were two conditional effects that emerged in this study that are noteworthy to discuss. First, more frequent cheating reduced happiness, but only in the individual condition compared to the group condition. The effect of cheating on happiness may be thought of as one's direct appraisal or evaluation of their behavior. When participants were completing the task alone, it may have been difficult for them to ignore their cheating and its effect of promoting their own interests. When completing the task as a group member, the tendency may have been to focus on how to enhance the value of one's in-group, rather than oneself, and excel at the task in order to outperform the out-group. Here, cheating may have been perceived as helping one's group rather than oneself. Additionally, in this study, since only the combined scores of the in-group were compared against the out-group, this provided sufficient anonymity and perhaps an added incentive for a group member to cheat. Such anonymity was not available in the individual condition. Taken together, while in the individual condition participants cheating behavior could have grabbed their attention, reminding them of their selfish motives, cheating in the group could 
be hidden from other group members, and participants may have seen their cheating as helping their group. The consequence was that for those completing the task alone, they were emotionally affected by their cheating while those completing the task as a group member were not.

While frequent cheating reduced happiness only for those carrying out the task alone, we also found that those who cheated while working alone were happier when they thought that others saw them as slightly less moral than how they saw themselves. This was the effect of the linear portion of the moral identity discrepancy. This was not evidenced for those working as a group. However, the happiness that was experienced for individuals working alone only occurred for a small amount of under-evaluation in one's moral identity. Beyond this small amount, the effect of the moral identity discrepancy on happiness was governed by the squared moral identity discrepancy in both conditions. Experiencing a discrepancy in the moral identity reduced happiness whether carrying out the task alone or as a group member. When participants thought others over-rated or under-rated them along the moral dimension, they were less happy than when they were rated according to how they saw themselves.

The act of cheating apparently activated thoughts about how others saw them in comparison to how they saw themselves along the moral dimension. This is taking into account the reflected appraisals (how participants think that others see them) rather than one's direct appraisals of their cheating. Irrespective of how individuals may have justified their cheating to themselves, when they considered the views of others, reports of happiness declined when they thought that others' views were discrepant with their own self-views.

We cannot speak to the persistence of feelings of happiness (or the lack thereof) after the participants left the laboratory. We have taken into account the feeling that individuals brought 
into the situation, but longitudinal data would be needed to identify whether and how emotions carry over from one situation to the next. In the case of happiness, previous research has discussed how positive emotions can serve as a resource, helping individuals to cope with subsequent negative information, and acting as a buffer that aids in the regulation of less favorable emotions (Fredrickson 1998; 2001). In this way, we would want to find ways to prolong feelings of happiness when they arise.

We also cannot speak to whether these effects would remain if individuals had a person identity and social identity that had the same dimension of meaning such as being "caring" and be categorized as a member of a "caring group." Here the meanings across identities overlap and might produce less distinctiveness in actors' feelings when the individual and group condition comparisons are made. Future research will want to explore this issue.

Finally, while the purpose of any experiment is to test one's theoretical predictions under carefully controlled conditions rather than make empirical generalizations, this study begins to give us some insight into how macro forces such as one's position in the status hierarchy and human capital and micro forces such as identity verification may coalesce to produce happiness in situations. The more often that a situation activates an identity, and the more individuals are exposed to identity verification, the more it may increase their happiness. Thus, while people's happiness may have to do with structural resources they enjoy, it may also have to do with identity resources that facilitate identity verification. 


\section{References}

Becker, Gary S. 1964. Human Capital. Chicago: University of Chicago Press.

Borgonovi, Francesca. 2008. "Doing Well by Doing Good: The Relationshpip between Formal Volunteering and Self-Reported Health and Happiness." Social Science and Medicine $66: 2321-2334$

Brickman, Philip, Dan Coates, and Ronnie Janoff-Bulman. 1978. "Lottery Winners and Accident Victims: Is Happiness Relative?" Journal of Personality and Social Psychology 36:917-927.

Burke, Peter J. and Jan E. Stets. 2009. Identity Theory. New York: Oxford University Press.

Buunk, Bram P., Rebecca L. Collins, Shelley E. Taylor, Nico W. VanYperen, and Gayle A. Dakoff. 1990. "The Affective Consequences of Social Comparison: Either Direction Has Its Ups and Downs." Journal of Personality and Social Psychology 59:1238-1249.

Carver, Charles S. and Michael F. Scheier. 1998. On the Self-Regulation of Behavior. New York: Cambridge University Press.

Davis, James A. 1984. "New Money, and Old Man/Lady and 'Two's Company': Subjective Welfafre in the Norc General Social Surveys, 1972-1982." Social Indicators Research $15: 319-350$.

Diener, Ed. 2008. "The Remarkable Changes in the Science of Subjective Well-Being." Perspectives in Psychological Science 8:663-666.

Diener, Ed, Richard E. Lucas, and Christie Napa Scollon. 2006. "Beyond the Hedonic Tradmill: Revising the Adaptation Theory of Well-Being." American Psychologist 61:305-314.

Diener, Ed, Eunkook M. Suh, Richard E. Lucas, and Heidi L. Smith. 1999. "Subjective WellBeing: Three Decades of Progress." Psychological Bulletin 125:276-302. 
Fazio, Russell H., Steven J. Sherman, and Paul M. Herr. 1982. "The Feature-Positive Effect in the Self-Perception Process: Does Not Doing Matter as Much as Doing?" Journal of Personality and Social Psychology 42:404-411.

Fredrickson, Barbara L. 1998. "What Good Are Positive Emotions?" Review of General Psychology 2:300-319.

—. 2001. "The Role of Positive Emotions in Positive Psychology: The Broaden-and-Build Theory of Positive Emotions." American Psychologist 56:218-226.

George, Linda K. 2010. "Still Happy after All These Years: Research Frontiers on Subjective Well-Being in Later Life." Journal of Gerontology 65:331-339.

Haidt, Jonathan and Jesse Graham. 2009. "Planet of the Durkheimians: Where Community, Authority, and Sacredness Are Foundations of Morality." Pp. 371-401 in Social and Psychological Bases of Ideology and System Justification, edited by J. T. Jost, A. C. Kay, and H. Thorisdottir. New York: Oxford.

Haidt, Jonathan and Selin Kesebir. 2010. "Morality." Pp. 797-832 in Handbook of Social Psychology, edited by S. T. Fiske, D. T. Gilbert, and G. Lindzey. New York: John Wiley and Sons.

Hauser, Marc. 2006. Moral Minds: How Nature Designed Our University Sense of Right and Wrong. New York: Harper Collins.

Kahneman, Daniel and Amos Tversky. 1979. "Prospect Theory: An Analysis of Decision under Risk." Econometrica 47:263-91.

Kalkhoff, Will and Robb Willer. 2008. "Deterring Deviance: Rationality and Self-Control." Pp. 39-61 in Experiments in Criminology and Law: A Research Revolution, edited by C. Horne and M. J. Lovaglia. Lanham, MD: Rowman and Littlefield. 
Lykken, David and Auke Tellegen. 1996. "Happiness Is a Stochastic Phenomenon." Psychological Science 7:186-189.

Lyubomirsky, Sonja 2001. "Why Are Some People Happier Than Others." American Psychologist 56:239-249.

Lyubomirsky, Sonja, Laura King, and Ed Diener. 2005. "The Benefits of Frequent Positive Affect: Does Happiness Lead to Success?" Psychological Bulletin 131:803-855.

Lyubomirsky, Sonja, Kennon M. Sheldon, and David Schkade. 2005. "Pursuing Happiness: The Architecture of Sustainable Change." Journal of General Psychology 9:111-131.

Merton, Robert. 1957. Social Theory and Social Structure. Glencoe, IL: Free Press.

Power, Mick. 2015. Understanding Happiness: A Critical Review of Positive Psychology. New York: Routledge.

Ross, Lee D. 1977. "The Intuitive Psychologist and His Shortcomings: Distortions in the Attribution Process." Pp. 173-220 in Advances in Experimental Social Psychology, edited by L. Berkowitz. New York: Academic Press.

Schnittker, Jason. 2008a. "Diagnosing Our National Disease: Trends in Income and Happiness, 1973 to 2004." Social Psychology Quarterly 71:257-280.

— 2008b. "Happiness and Success: Genes, Families, and the Psychological Effects of Socioeconomic Position and Social Support." American Journal of Sociology 114:233-259. Shelly, Robert K. and Lisa Troyer. 2001. "Emergence and Completion of Structure in Initially Undefined and Partially Defined Groups." Social Psychology Quarterly 64:318-332.

Shelly, Robert K., Lisa Troyer, Paul T. Munroe, and Tina Burger. 1999. "Social Structure and the Duration of Social Acts." Social Psychology Quarterly 62:83-95. 
Shelly, Robert K. and Murray Webster, Jr. 1997. "How Formal Status, Liking, and Ability Status Structure Interaction: Three Theoretical Principles and a Test." Sociological Perspectives 40:81-107.

Smith, Richard H. 2000. "Assimilative and Contrastive Emotional Reactions to Upward and Downward Social Comparisons." Pp. 173-200 in Handbook of Social Comparison: Theory and Research, edited by J. Suls and L. Wheeler. New York: Kluwer Academic/Plenum. Spranca, Mark, Elisa Minsk, and Jonathan Baron. 1991. "Omission and Commission in Judgment and Choice." Journal of Experimental Social Psychology 27:76-105.

Stets, Jan E. 2011. "Applying Identity Theory to Moral Acts of Commission and Omission." Advances in Group Processes 28:97-124.

Stets, Jan E. and Peter J. Burke. 2014a. "Emotions and Identity Non-Verification." Social Psychology Quarterly 77:387-410.

—. 2014b. "Social Comparison Processes in Identity Theory." Pp. 39-59 in Communal Functions of Social Comparison, edited by Z. Krizan and F. X. Gibbons. New York: Cambridge University Press.

Stets, Jan E. and Michael J. Carter. 2011. "The Moral Self: Applying Identity Theory." Social Psychology Quarterly 74:192-215.

—. 2012. "A Theory of the Self for the Sociology of Morality." American Sociological Review $77: 120-140$.

Stevenson, Betsey and Justin Wolfers. 2008. "Happiness Inequality in the United States." Journal of Legal Studies 37:533-579.

—. 2009. "The Paradox of Declining Female Happiness." American Economic Journal: Economic Policy 1:190-225. 
—. 2013. "Well-Being and Income: Is There Any Evidence of Satiation?" American Economic Review 103:598-604.

Tajfel, Henri and John C. Turner. 1979. "An Integrative Theory of Intergroup Conflict." Pp. 3347 in The Social Psychology of Intergroup Relations, edited by W. G. Austin and S. Worchel. Pacific Grove, CA: Brooks/Cole.

Turner, John C., Michael A. Hogg, Penelope J. Oakes, Stephen D. Reicher, and Margaret S. Wetherell. 1987. "Rediscovering the Social Group: A Self-Categorization Theory." New York: Basil Blackwell.

Veenhoven, Ruut. 1991. "Is Happiness Relative." Social Indicators Research 24:1-34.

—. 2008. "Sociological Theories of Subjective Well-Being." Pp. 44-61 in The Science of Subjective Well-Being: A Tribute to Ed Diener, edited by M. Eid and R. Larsen. New York: Guilford.

Wheeler, Ladd. 2000. "Individual Differences in Social Comparison." Pp. 141-158 in Handbook of Social Comparison: Theory and Research, edited by J. Suls and L. Wheeler. New York: Kluwer Academic/Plenum.

Wrosch, Carsten, Gregory E. Miller, Michael F. Scheier, and Stephanie Burn de Pontet. 2007. "Giving up on Unattainable Goals: Benefits for Health?" Personallity and Social Psychology Bulletin 33:251-65.

Yang, Yang. 2008. "Social Inequalities in Happiness in the United States, 1972 to 2004: An AgePeriod-Cohort Analysis." American Sociological Review 72:204-226. 